\title{
NICHROME THIN FILM TECHNOLOGY AND ITS APPLICATION
}

\author{
JOACHIM RÖLKE
}

Siemens AG, Munich, W-Germany

\begin{abstract}
$\mathrm{NiCr}$ thin film resistors are widely used in the current resistor technology. Ranging from discrete resistors up to highest performance hybrid integrated circuits, vacuum deposited $\mathrm{NiCr}$ alloys cover extreme areas of application. Depending upon $\mathrm{NiCr}$ composition, process parameters, substrate and conductor materials, resistors with extremely low temperature coefficient of resistance (TCR) and high stability, low noise and distortion can be produced. $\mathrm{NiCr}$ resistors therefore offer particular advantages for applications with special demand for high stability as well as low TCR-like selected circuits for measuring equipment, data processing, telecommunication. etc.
\end{abstract}

\section{INTRODUCTION}

One of the characteristics of the transition metal alloys is their interesting behaviour concerning applications as resistive material:

Comparative high resistivity

Low Temperature Coefficient of Resistance (TCR)

High stability of electrical properties

This behaviour led to wide application of these alloys (sometimes alloyed with $\mathrm{Fe}, \mathrm{Al}, \mathrm{Cu}$ ) as resistive material for wire wound resistors. ${ }^{1,10}$

TABLE I

Resistivity and TCR of bulk NiCr alloys

\begin{tabular}{lll}
\hline Composition & Resistivity & TCR \\
\hline wt-\% & $\mu$ ohmcm & $\mathrm{ppm} / \mathrm{K}$ \\
$\mathrm{Ni}(80) \mathrm{Cr}(20)$ & 110 & +85 \\
$\mathrm{Ni}(76) \mathrm{Cr}(20) \mathrm{Al}(2) \mathrm{Fe}(2)$ & 133 & \pm 5 \\
\hline
\end{tabular}

The knowledge about the favorable properties of $\mathrm{Ni}-\mathrm{Cr}$ alloys for electrical applications obviously initiated intense work to deposit them by vacuum techniques in form of thin films, at first surely not fully understanding and appreciating the additional electrical advantages of vacuum deposited thin films, such as higher resistivity and lower TCR.

Discussing the behaviour of thin $\mathrm{NiCr}$ films we should consider:

a) The behaviour of a "real" resistor is determined not only by the performance and reliability of the resistive material itself; rather the properties of the resistors include the influence of the terminations, the interconnections, the substrate, layout design, sealing, environment, etc.

b) The performance of thin film resistors can be influenced positively by suitable vacuum processes, specific vacuum conditions and careful choice of all materials from a metallurgical point of view. $\mathrm{NiCr}$ thin film circuits are produced generally by applying the well known thin film process steps:

Vacuum deposition

Photolithographic processing

Stabilisation

Trimming

Assembling

Sealing

Next, we will discuss some selected and characteristic aspects of $\mathrm{NiCr}$ technology with respect to production, performance and reliability.

\section{NiCr RESISTOR FILMS}

\subsection{Deposition}

Some electrical properties of $\mathrm{NiCr}$ films strongly depend on the NiCr ratio (Figures 1, 2). It is well known 


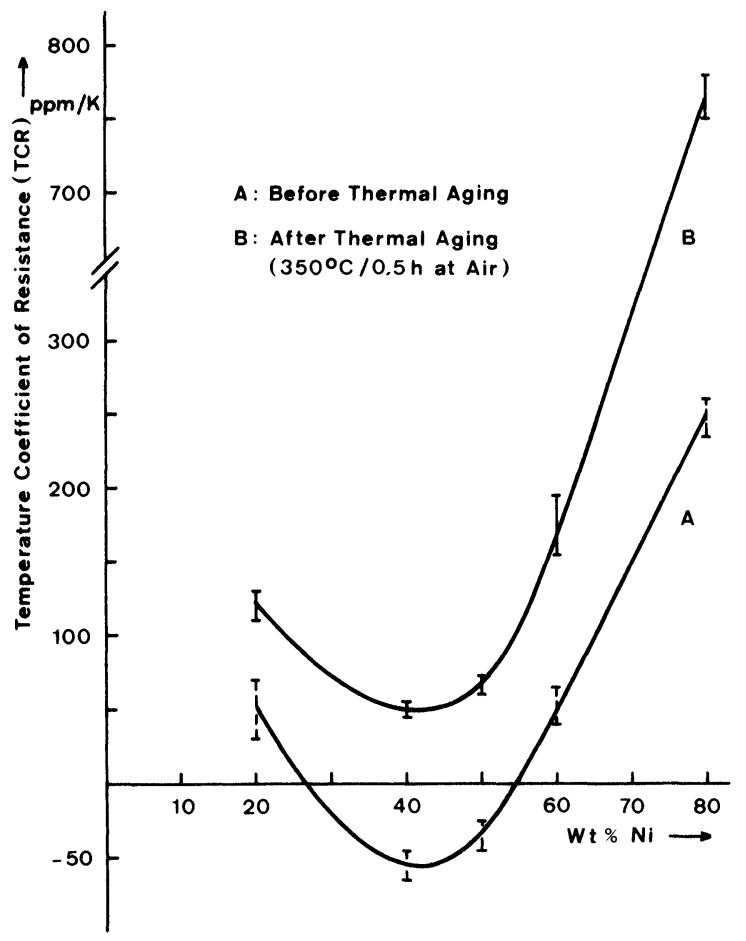

FIGURE 1 Influence of $\mathrm{NiCr}$ composition on TCR.

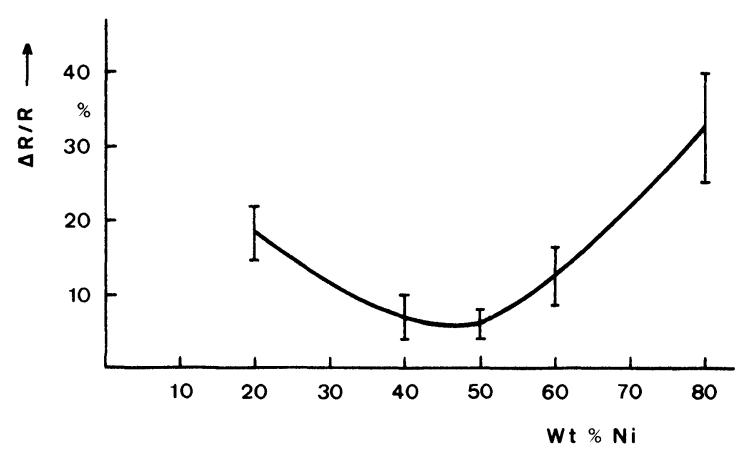

FIGURE 2 Influence of $\mathrm{NiCr}$ composition on resistance change during stabilization treatment $\left(350^{\circ} \mathrm{C}, 0.5 \mathrm{~h}\right)$.

that thermal evaporation of $\mathrm{NiCr}$ from a finite mass of molten alloy causes a film composition change away from the composition of the source. Besides the film composition changes from run to run. Therefore flash evaporation of $\mathrm{NiCr}$ powder or wires ${ }^{1}$ or sputtering ${ }^{2}$ are recommended methods to ensure reproducibility. But in order to understand the behaviour of thin $\mathrm{NiCr}$ resistor films completely, we have to take into account some phenomena such as incorporated impurities, imperfections, crystal structures, etc. In this connection the following process parameters are of special interest:

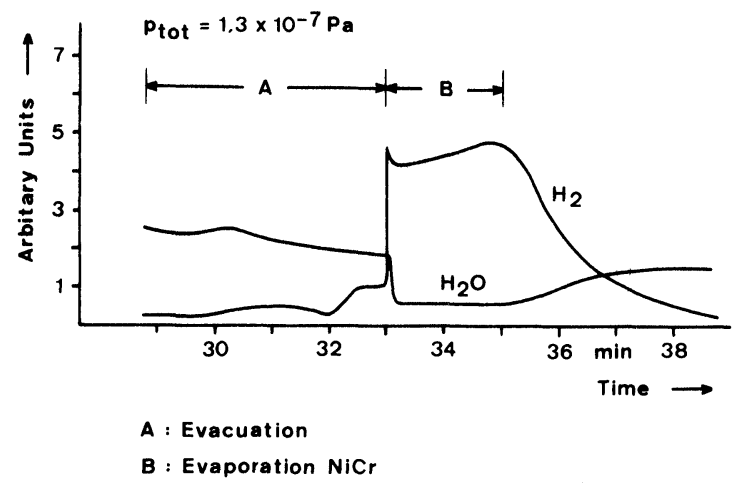

FIGURE 3 Partial pressure of $\mathrm{H}_{2} \mathrm{O}$ and $\mathrm{H}_{2}$ before and during evaporation.

Residual atmosphere and deposition rate $2,3,4,5$ (Figure 4).

Substrate temperature during deposition ${ }^{12}$

Film thickness ${ }^{11}$

Substrate material and surface ${ }^{1,12}$

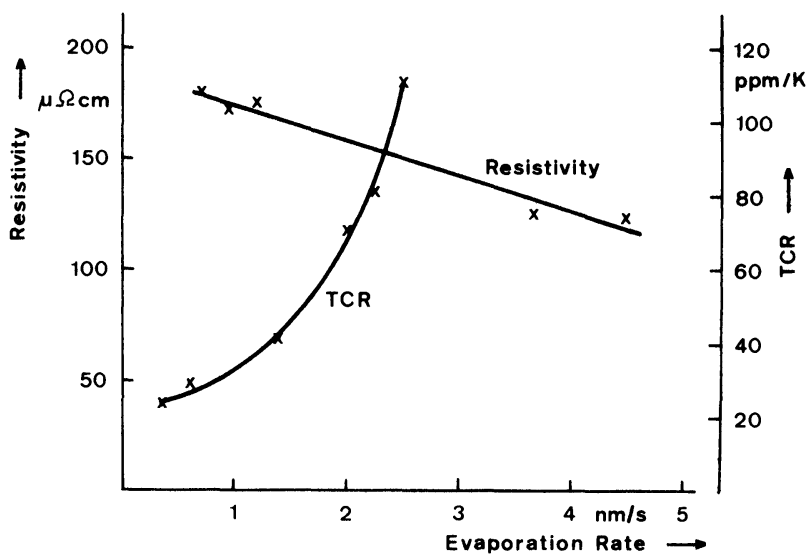

FIGURE 4 Influence of evaporation rate on TCR and resistivity.

Of some major importance is - due to the affinity of $\mathrm{Cr}$ for oxygen - the influence of the latter on structure and electrical behaviour (TCR, stability, resistivity). The main source of oxygen and other detectable impurities during deposition are constituents of the residual atmosphere: Oxygen, originated by splitting $\mathrm{H}_{2} \mathrm{O}$-molecules as is shown by mass spectra analysis during deposition (Figure 3 ). Therefore, a strict control of vacuum and deposition data is absolutely necessary to produce thin film $\mathrm{NiCr}$ resistors with closely tolerated and reproducible electrical behaviour. 
On the other hand, it is possible to utilize the strong oxygen dependence by reactive sputtering in an $\mathrm{Ar} / \mathrm{O}_{2}$-mixture. By choice of a suitable oxygen partial pressure, followed by a sufficient post deposition heat treatment, stable resistors with low and closely tolerated TCR can be produced ${ }^{2}$ (Figure 5).

Incorporating a third metallic constituent is another way to produce resistors with near zero TCR. Ternary alloys of $\mathrm{NiCrSi}^{6}$ and $\mathrm{NiCrAu^{7 }}$ of suitable composition are reported to provide films with low TCR and high stability too.

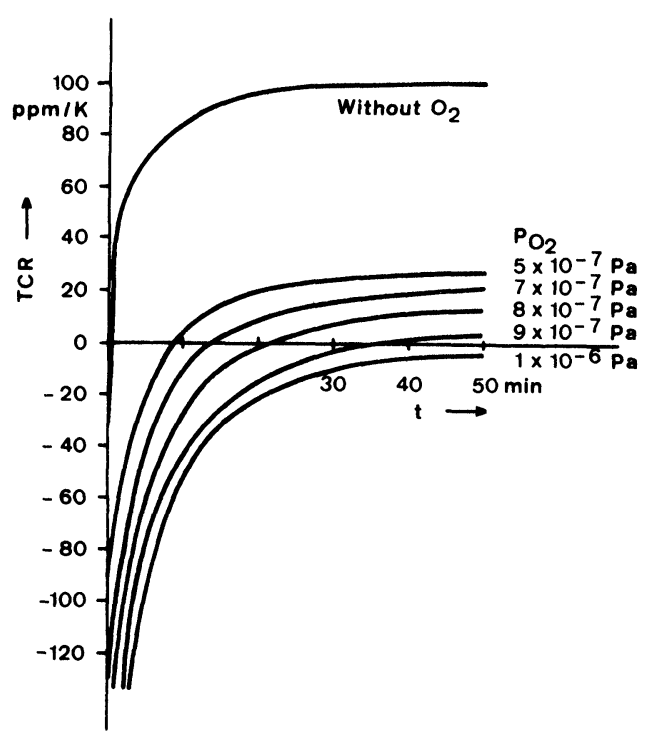

FIGURE 5 Influence of $\mathrm{O}_{2}$ partial pressure and stabilization time on TCR. Annealling temperature: $350^{\circ} \mathrm{C}$. $^{2}$

\subsection{Thermal aging and film structure}

Freshly deposited thin films generally contain a great number of structural defects, which considerably determine the electrical behaviour of the film. Being greatly beyond thermodynamic equilibrium, such imperfect films show a tendency of self annealing by minimizing their total energy. Generally, this leads to a remarkable change in resistivity and TCR. Thus, thermal aging during and/or after deposition is necessary to stabilize the film properties.

As Figure 6 (A) shows, $\mathrm{NiCr}$ films annealed in high vacuum, show a remarkable increase of TCR and a decrease of resistivity. It is assumed that this change is due to grain-size growth and decrease of grain-boundary area.

In presence of oxygen (Figure $6(\mathrm{~B})$ ), the increase of TCR is diminished due to formation of an oxide phase

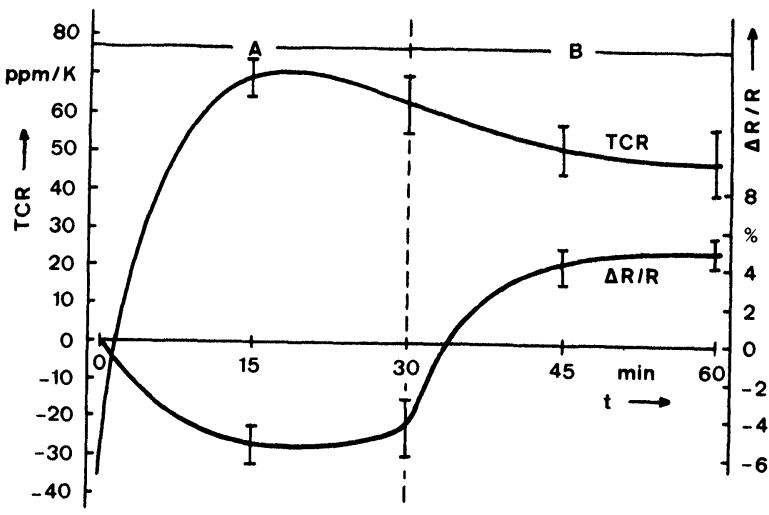

$$
\begin{aligned}
& \text { A: High Vacuum }(10-7 \mathrm{~Pa}) \\
& \text { B : Air }
\end{aligned}
$$

FIGURE 6 Change of TCR and resistivity during heat treatment. Temperature: $350^{\circ} \mathrm{C}$.

$\left(\mathrm{Cr}_{2} \mathrm{O}_{3}\right)$ with negative TCR. Figure 1 shows the composition influence on TCR change during heat treatment. There is a considerable increase of TCR for $\mathrm{Ni}$ rich films, due to precipitation and oxidation of $\mathrm{Cr}$ during annealing. ${ }^{4}$

The structure of thin $\mathrm{NiCr}$ film depends considerably upon the deposition conditions. The equilibrium phase diagram of bulk $\mathrm{NiCr}$ shows a large immiscibility gap between two solid solutions (Figure 7):

bcc $\alpha-\mathrm{Cr}$ with incorporated $\mathrm{Ni}$ fcc $\gamma$-Ni with incorporated $\mathrm{Cr}$

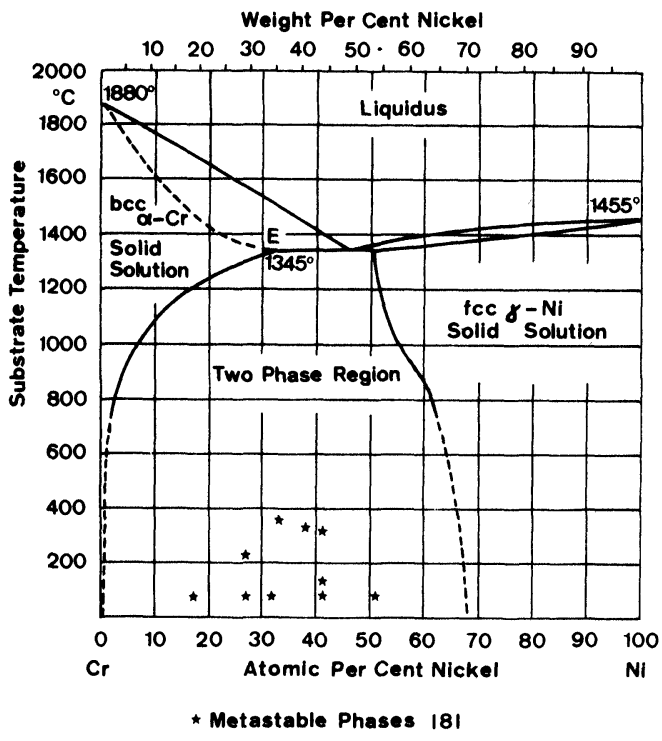

FIGURE 7 Phase diagram of bulk NiCr. 
This wide immiscibility, the relatively deep eutectic and the capability of $\mathrm{NiCr}$ to form metallic compounds are reported to favour the appearance of metastable phases. ${ }^{8,9}$ In Figure 7 star-shaped marks show the compositions and substrate temperatures at which metastable phases have been detected. It should be mentioned, that their formation is limited to very particular conditions (substrate type and temperature, deposition rate, film thickness, pressure, etc); therefore, in practice, in many cases they don't occur. But if they are present in the film, their considerable influence on resistivity and stability has to be taken into account. As deposited $\mathrm{NiCr}$ films show, depending upon the substrate temperature during deposition, an amorphous, highly distorted or fine-grained structure can result. By heat treatment at air, grain-size growth and oxidation is enforced. ${ }^{13}$ Thereby, film stability increases by anticipation of otherwise spontaneously occurring processes. The best stabilization conditions may be determined empirically by measuring stability versus time and temperature of heat treatment. ${ }^{14}$

\subsection{Substrates}

The electrical properties and the stability of $\mathrm{NiCr}$ resistor films are considerably influenced by physical and chemical interactions between film and substrate surface. ${ }^{5,16,18}$ Thus, the yield of production greatly depends upon the uniformity and reproducibility of substrate properties, such as surface roughness (Figures $8,9)$, texture, flatness, chemical composition, etc. Any choice of substrate material for a particular application is determined by such quite different aspects as power dissipation, required stability, TCR, costs, etc. Thus, in thin film technology alternative materials are used:

Borosilicate glasses

Polycrystalline alumina, glazed or as fired

Silicon wafers

Polyimide $^{17}$

Advantages and disadvantages of the above materials are discussed shortly:

Borosilicate glasses: High uniformity and reproducibility of resistance, (Figure 9), low TCR, high resistor stability, low thermal conductivity, low mechanical strength, fairly low costs.

As fired thin film alumina (99.5\%): High thermal conductivity, high mechanical strength, lower uniformity (Figure 9), reproducibility and stability (Figure 10) of resistor parameters, fairly high costs.

Glazed alumina: Properties and costs between glass and as fired alumina, reduced mechanical strength due to the glaze.

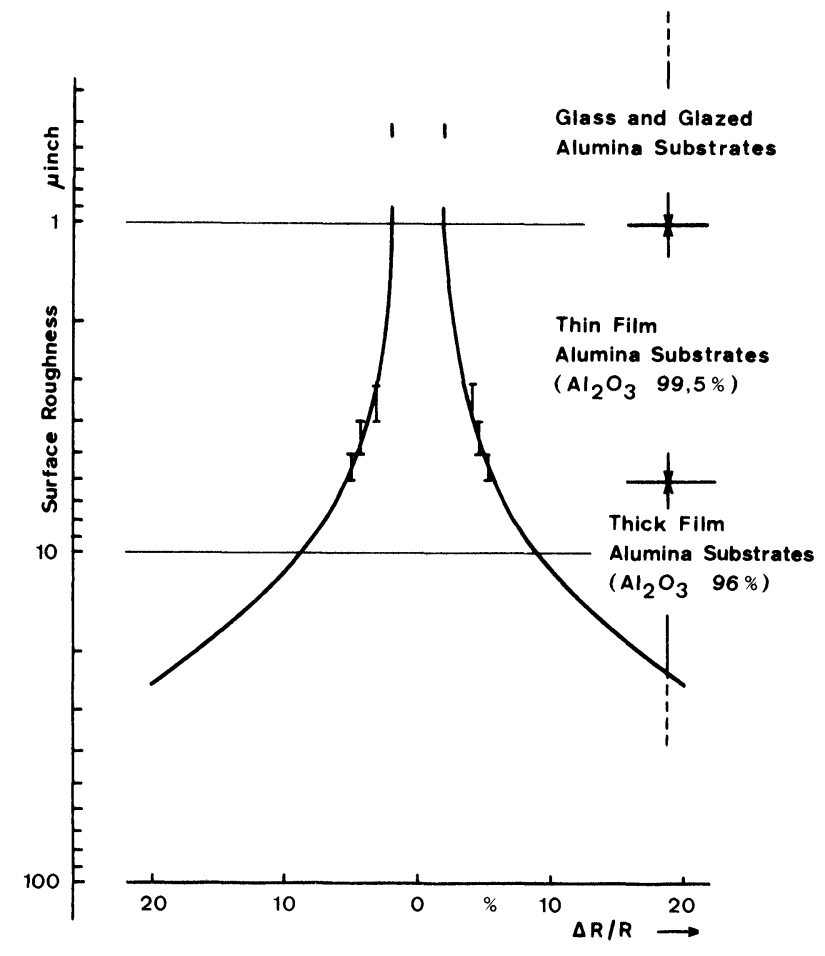

FIGURE 8 Influence of surface roughness on resistor spread. One substrate for each substrate type. (73 resistors).

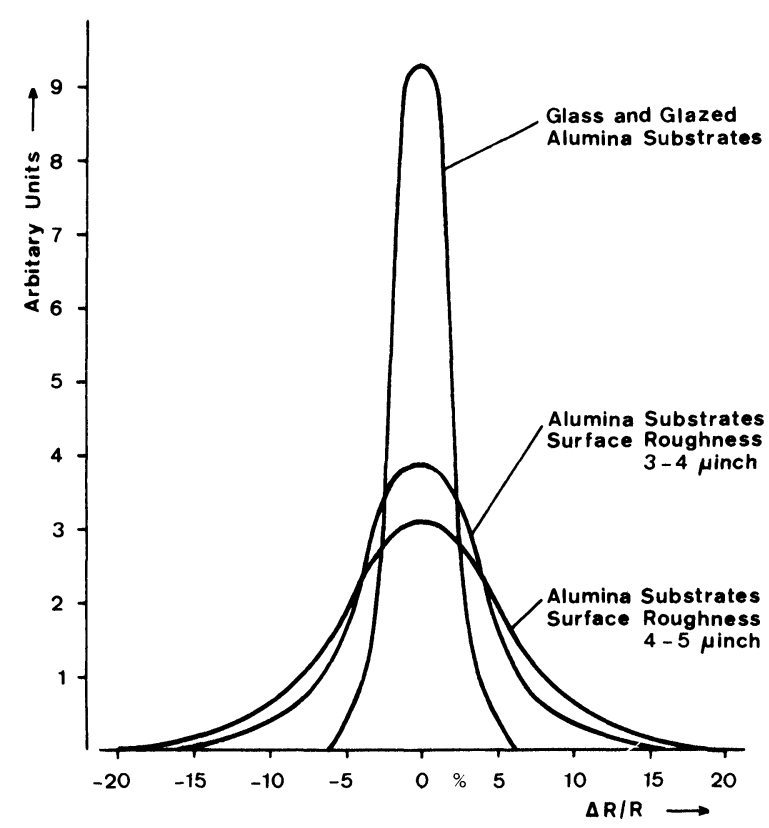

FIGURE 9 Influence of surface roughness on resistor uniformity and reproducibility across 50 substrates $(3650$ resistors) for each substrate type. 
Oxidized silicon wafers: High performance material, but also high costs.

Polyimide: A recent development, cheap in mass production by continuous band processing. Nevertheless considerable high resistor performance. ${ }^{17}$

\section{TERMINATIONS AND CONDUCTOR MATERIALS}

A "real" thin film resistor consists of three parts: the resistor film, the conductor and an interfacial film between both. Technological shortcomings concerning these films and/or insufficient layout design may impair the high performance of the resistive material by increasing TCR and current noise, and decreasing the long term stability. ${ }^{19}$ To insure an adequate bond to the resistive film, usually a chemically active material (e.g. $\mathrm{Ti}, \mathrm{Cr}$ ) is deposited between resistor and conductor film. By combining metallurgically unsuitable materials, a remarkable increase of interfacial resistance may occur due to interdiffusion, forming intermetallic compounds with high resistivity. Further, conductor films, evaporated at higher angles of incidence, may show a porous structure, thus supporting electrocorrosion or oxidation of the adhesion layer. ${ }^{20}$ The adhesion strength of such conductors may decrease and a higher current noise can occur.

Besides metallurgical processes at the resistor/ conductor interface, similar processes on top of the conductor have to be considered. Depending upon the assigned assembling techniques (bonding, soldering), demands for high frequency stability (e.g. MIC's) and cost efficiency, different metallizations for different applications are usual. Thus, in $\mathrm{NiCr}$ thin film technology a wide spectrum of materials and combinations of materials can be found for conductor application, e.g.: $\mathrm{Al},{ }^{21} \mathrm{Cu},{ }^{17} \mathrm{Au},{ }^{16} \mathrm{PdAu},{ }^{22} \mathrm{NiAu} .{ }^{14}$

\section{NiCr RESISTOR PROPERTIES AND RELIABILITY}

The main advantage of $\mathrm{NiCr}$ thin film resistors is their high stability in combination with very low TCR, an indispensable requirement for circuits with demand for extremely high stability of electrical function. Table II shows typical data of $\mathrm{NiCr}$ resistors in hybrid integrated circuits:

Resistor stability is usually evaluated by accelerated life tests at elevated temperatures with or without additional electrical load. Within limited temperature
TABLE II

Properties and reliability of $\mathrm{NiCr}$ resistors

\begin{tabular}{lll}
\hline & Units & Range \\
\hline Sheet resistance & $\mathrm{ohm} / \mathrm{sq}$ & $30-300$ \\
Resistance & $\mathrm{ohm}$ & $10-10 \mathrm{M}$ \\
Tolerance & $\%$ & $\pm 0.01^{a}$ \\
TCR & $\mathrm{ppm} / \mathrm{K}$ & $0 \pm 10-50$ \\
Tracking of TCR & $\mathrm{ppm} / \mathrm{K}$ & $1-3$ \\
Stability $\Delta R / R^{b}$ & $\% o$ & $0.5^{c}-2^{d}$ \\
Tracking of $\Delta R / R^{b}$ & $\% o$ & $0.2-0.4$ \\
Current noise index $A$ & $\mathrm{~dB}$ & $-40^{e}$ \\
Distortion index $A_{3}$ & $\mathrm{~dB}$ & $120^{c}-150^{d f}$ \\
\hline
\end{tabular}

${ }^{a}$ Laser trimmed

${ }^{b}$ Storage at $125^{\circ} \mathrm{C}, 0.5 \mathrm{~h}$

${ }^{c}$ Alkali free glass

${ }^{d 99,5 \%}$ Alumina (as fired)

${ }^{e} A=20 \log E_{1} / U$, Measurement method DIN 44049

${ }^{f_{A_{3}}}=20 \log U_{1} / E_{3}$, Measurement method DIN 44049

range the resistance drive $\Delta R / R$ is proportional to $t^{1 / n}$ with $n$ between $2^{25}$ and 4, depending upon processing and film structure ${ }^{26}$ (Figure 10). Concerning the temperature dependence, a linear relationship exists between $\log \Delta R / R$ and $1 / T$, being typical for thermal activated processes. This can be used to predict long term stability at the operation temperature: We found by thermal analysis and extrapolation a resistance drift of $\mathrm{NiCr}$ films on as fired alumina (Figure 10) less than $1 \%$ after 15 years operation at $70^{\circ} \mathrm{C}$.

In practice, long term stability may be deteriorated by superimposed additional processes like ion-migration, chemical or electrochemical corrosion. The former process may occur due to choice of unsuitable (e.g. sodium rich) substrate material. ${ }^{24}$ The

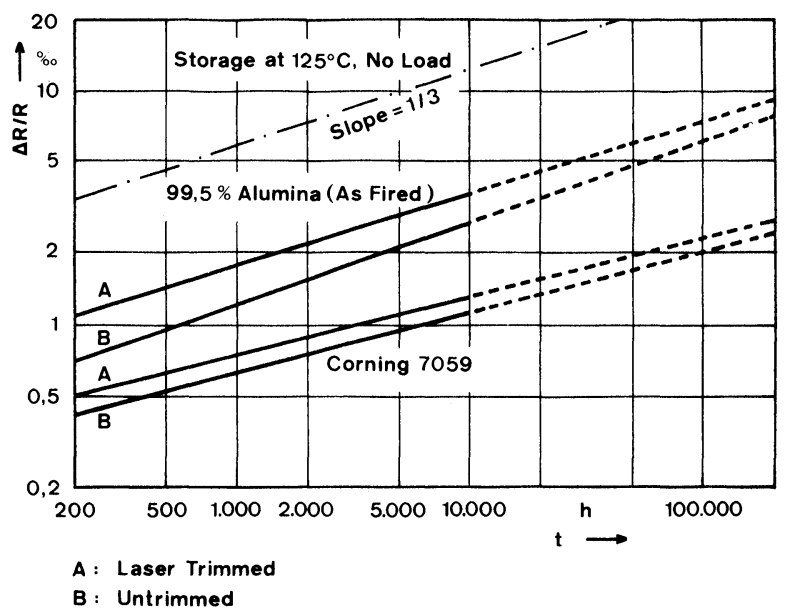

FIGURE 10 Resistor stability for different substrate materials. $\Delta R / R=t^{1 / 3}$ 
latter is related to the sensitivity of $\mathrm{Ni}$ - and $\mathrm{Cr}$ - oxides (or the resistor/conductor interface) to electrochemical attack in presence of condensed moisture, possibly participating residual chemicals from etchants or gasses of industrial environment. ${ }^{21}$ Therefore, the carefully rinsed circuits generally have to be sealed with coatings either on silicone basis, or silicon monoxide, -dioxide, -nitride, borosilicate glass, etc. ${ }^{21,23,24,27}$ Circuits operating frequently below dew point conditions should be mounted into hermetically sealed packages, and the residual vapor content has to be low enough to safely prevent moisture condensation at the lowest possible storage- or operation temperature.

\section{APPLICATIONS}

$\mathrm{NiCr}$ alloys, deposited by vacuum methods, are widely used in the current resistor technology. $\mathrm{NiCr}$ films cover extreme areas of application reaching from discrete resistors to highest performance integrated resistor networks. ${ }^{28,29}$

In detail, we find large volume production of discrete $\mathrm{NiCr}$ film resistors at adequate quality and low cost for main requirements, on the other hand high quality resistors with low TCR, high stability and low tolerance of TCR and resistance.

In the hybrids field $\mathrm{NiCr}$ thin film resistors offer specific advantages by the combination of very low TCR with high stability, low noise and distortion ${ }^{5}$ (Figure 11). Thus, NiCr thin film technology is the

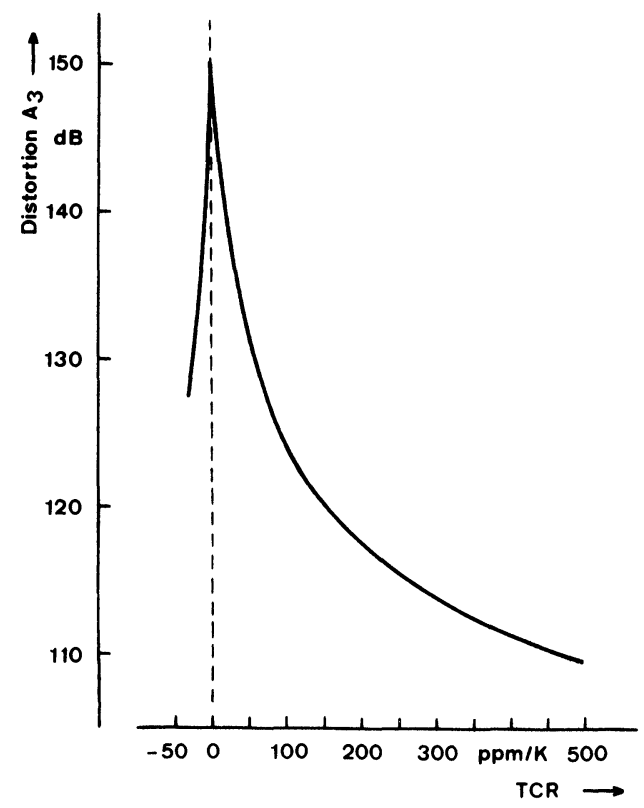

FIGURE 11 TCR vs. distortion index $A_{3}$.

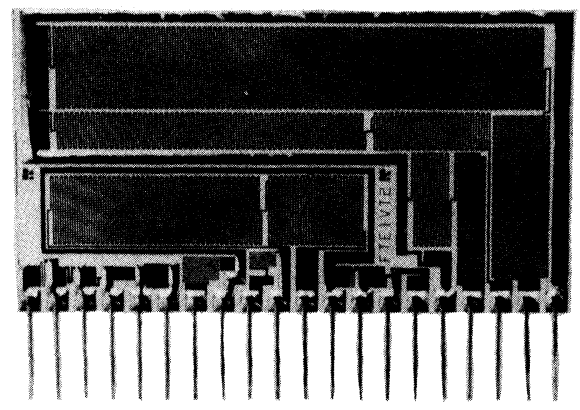

FIGURE 12 Voltage divider for X-Y-plotter.

choice technology for resistors and hybrids for measuring equipment, for data processing and for special applications in the telecommunication field with demand for high stability of electrical function.

Typical applications therefore may be voltage dividers (Figure 12) or instrumentation amplifiers for measuring equipment, R-2R-ladder networks (Figure 13) and reference circuits for $A / D$ and $D / A$ converters, ${ }^{30,31}$ submerged repeaters or attenuation networks for long-range communication, ${ }^{25}$ or to some extent active filters for telecommunication. ${ }^{31}$

Concerning the latter, highly stable filters can be built up by combining $\mathrm{NiCr}$ resistors of zero TCR with NPO chip capacitors; $;^{31,2}$ and this, for small production runs,

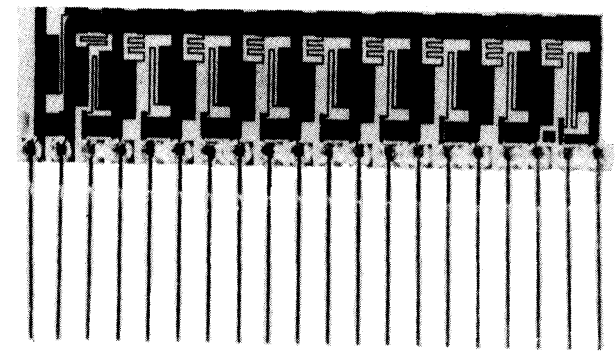

FIGURE 13 R-2R-ladder for D/A converter. 
at adequate costs. But an analysis of costs also shows that at increasing production rates integrated $\mathrm{R}-\mathrm{C}$ thin film technologies become increasingly economical. This is due to the fact that the cost per capacitor chip decreases very slowly with increasing quantities. On the other hand, integrated components start with high cost at small volume production, but decrease rapidly as the additional investment is spread across a large production. Further cost reduction is caused by less effort in assembling, due to the reduced number of components to be mounted. Thus, for filters, oscillators or similar applications integrated thin film (and increasingly thick film) hybrid technologies are preferred. Among these, tantalum-based thin film technologies are of importance, due to the excellent suitability of tantalum for both resistor - and thin film capacitor fabrication. ${ }^{32}$ In the past, we therefore developed parallel to $\mathrm{NiCr}$ an integrated hybrid $\mathrm{R}-\mathrm{C}$ technology with $\mathrm{TaAl}$ resistors and TaAl-Oxid/SiO $\mathrm{S}_{2}$ dielectric for capacitors to cover the above applications. ${ }^{33}$

To round up the picture, it should be mentioned that $\mathrm{NiCr}$ is used for some other applications, for example radiation hardened circuits, ${ }^{34}$ fusible links in PROM's, ${ }^{21}$ resistance standards (e.g. $1000 \mathrm{M}$ with TCR of less than $3 \mathrm{ppm} / \mathrm{K}$ !) ${ }^{35}$ and recently thermal printheads. ${ }^{23}$

\section{REFERENCES}

1. Maissel, Glang: Handbook of Thin Film Technology, McGraw-Hill, New York, (1970).

2. J. Griessing, Electrocomponent Science and Technology, 4, 133-137 (1977).

3. N. G. Dhere et al, Thin Solid Films, 59, 33-41 (1979).

4. L. Lassak and K. Hieber, Thin Solid Films, 17, 105-111 (1973).

5. J. G. Swanson and D. S. Campbell, Thin Solid Films, 1, 183-202 (1967).

6. R. Kaneoya, T. Matsumoto and K. Moriya, Review of the Electrical Communication Laboratories, 22, 82-91 (1974).

7. R. A. Thiel and E. H. Maurer, Proceedings 29th Electronic Components Conference, 151-157 (1979).

8. M. I. Birjega et al, Thin Solid Films, 34, 153-155 (1976).
9. C. Sarbu et al, Thin Solid Films, 28, 311-322 (1975).

10. G. W. A. Dummer, Materials for Conductive and Resistive Functions, Hayden Book Company, New York, 246-247.

11. D. S. Campbell and B. Hendry: Brit. J. Appl. Phys. 16, 1719 (1965).

12. H. Delfs and E. Salzmann, Aufgedampfte Dünnschichtschaltungen auf keramischen Substraten BMFT, Forschungsbericht T 76-26 (1976).

13. G. Nocerino and K. E. Singer, J. Vac. Sci. Technol. 16, (2) 147-150 (1979)

14. I. Ahern and K. Heid, IEEE Trans. PHP-8, June 72, No. $2,10$.

15. H. P. Lorenz and H. W. Pötzlberger, Nachrichtentechn. Z. 27, 190-195 (1974).

16. I. J. Faith and I. W. Jennings, Microelectronics and Reliability, 14, 41-48 (1975)

17. K. H. Houska European Hybrid Microelectronics Conference 1979, 399-409.

18. H. J. Degenhart and J. H. Pratt, Trans. Vac. Symp. 10th Boston, 480 (1963).

19. J. S. Fisher and P. M. Hall, Proceedings of IEEE, 1418-1424 Oct (1971).

20. J. J. Garido, D. Gerstenberg and R. W. Berry, Thin Solid Films, 41, 87-103 (1977).

21. C. H. Lane, Nichrome Resistor Properties and Reliability, Report RADC-TR-73-181, 6/73.

22. J. M. Morabito, J. H. Thomas and N. G. Lesh, IEEE Trans. on Parts, Hybrids, and Packaging, Vol. PHP-11, No. 4 (1975).

23. G. Zinsmeister, European Hybrid Microelectronics Conference 1979, Ghent, 149-160.

24. U. Smith and R. Hofmann, Electrocomponent Science and Technology, 5, 159-164 (1978).

25. D. O. Spiller, Proceedings European Hybrid Microelectronic Conference Bad Homburg, May 1977, XI.

26. J. S. Fisher, Proceedings Electronic Conference 1968, 299-303.

27. K. Heid, Proceedings Electronic Components Conference 1977, 68-71.

28. A. Engl, Electro-Anz, 7, Jg., 1975, Nr. 2, 41-44.

29. F. Hegner, Vakuum-Technik, 27, Jg., Nr. 5.

30. J. Szmolnik, Thin Solid Films, 36, 379-382 (1976).

31. L. Groth, Electronic Components Conference 1976, 317-321.

32. W. D. Weestwood, N. Waterhouse and P. S. Wilcox, Tantalum Thin Films, Academic Press, New York, 1975.

33. H. W. Pötzlberger, Proceedings European Hybrid Microelectronic Conference 1977, Bad Homburg, XIII.

34. W. F. Keenan and W. R. Runyan, Microelectronics and Reliability, 12, 125-138 (1973).

35. R. M. Blythe and H. S. Lowes, Proc. Euromeas., 1977, IEE, London. 

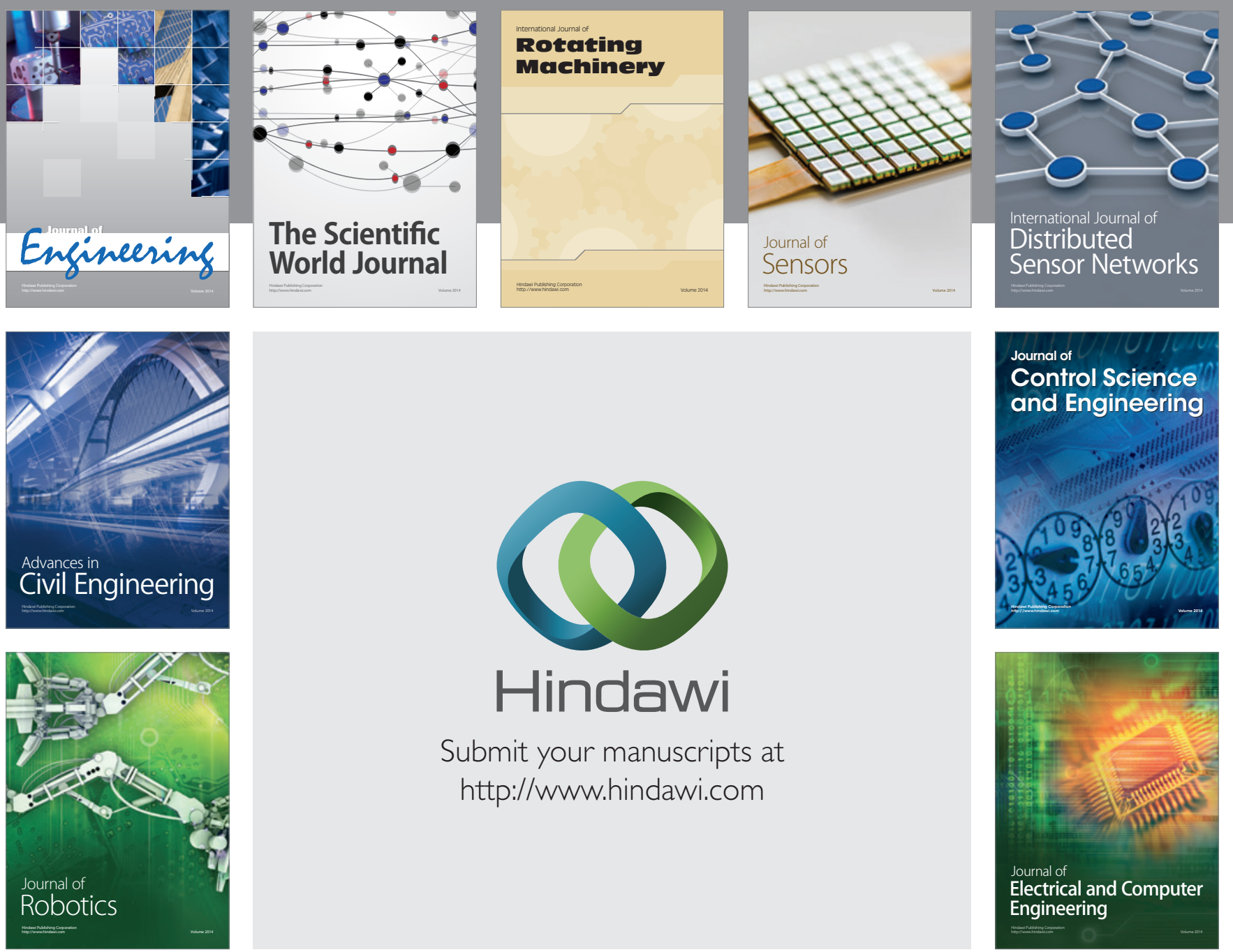

Submit your manuscripts at

http://www.hindawi.com
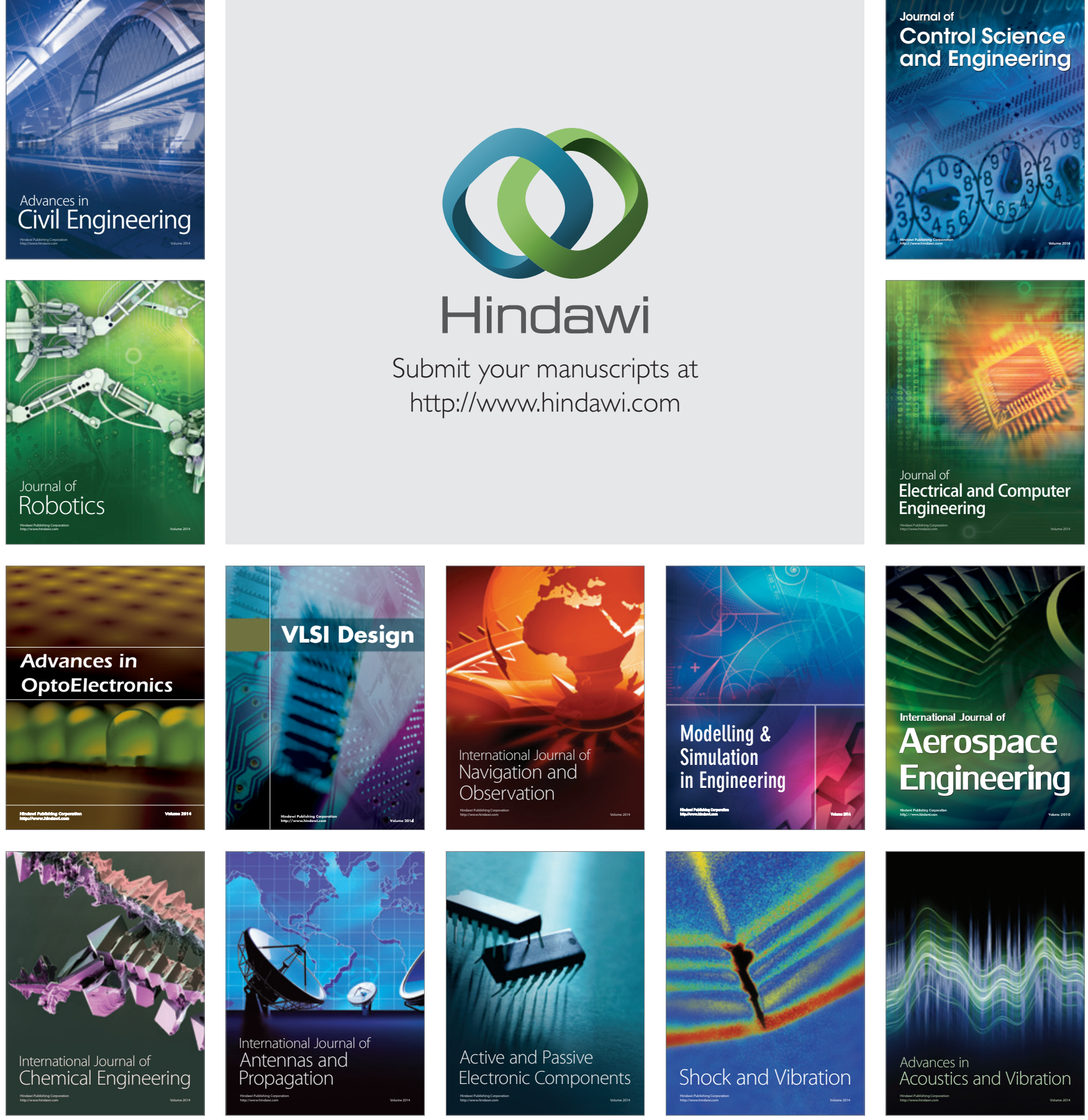